DUARTE, Mel (Org.). Querem nos calar: poemas para serem lidos em voz alta. São Paulo: Planeta Brasil, 2019, 224 p. ISBN 9788542215953

\title{
A IMPETUOSIDADE DAS VOZES NA POESIA: AS POETAS E O POETRY SLAM
}

\section{THE IMPETUOSITY OF VOICES IN POETRY: THE POETS AND THE POETRY SLAM}

\author{
Douglas Rosa da Silva ${ }^{1}$
}

Querem nos calar: poemas para serem lidos em voz alta é um livro que desarma as instâncias constitutivas de nosso tempo. A antologia, publicada em 2019, é organizada pela poeta, slammer e produtora cultural Mel Duarte. O livro é mais um dos exemplos que atestam a força do poetry slam no Brasil. Falando alto, para que a inteligibilidade da voz poética seja nítida e certeira, é recomendável que o leitor escute, página a página, os modos estratégicos de sobrevivência, os confrontos diários, e as histórias de vida e novas perspectivas que são evocadas pelos versos.

De forma panorâmica, pode-se afirmar que a coletânea de poemas Querem nos calar (2019) faz um exercício de marcar o momento efervescente do poetry slam no cenário nacional. As intenções da obra, no entanto, não podem ser reduzidas a este marco literário - que também é um marco cultural e social. No livro, a experiência delineada pela linguagem poética estabelece vínculos com sentidos que são construídos a partir de realidades marginalizadas. Os limites estéticos e visuais da escrita também são tensionados. A antologia viabiliza um amplo espaço para que as mulheres, em especial as mulheres negras, explorem e partilhem entendimentos que são frutos de suas vivências. De configuração histórica, as vozes das poetas reunidas na antologia falam a partir de um campo de subjetividades insubordinadas, impetuosas. A obra, como um todo, se coloca como um espetáculo explosivo, que reúne replicação e afeto, protesto e alteridade. Os escritos acentuam e elaboram críticas veementes às estruturas de poder que alavancam as desigualdades, as opressões, os genocídios, e as injustiças

\footnotetext{
${ }^{1}$ Doutorando em Estudos de Literatura, na linha de pesquisa de Teoria, Crítica e Comparatismo, do Programa de Pós-Graduação em Letras da Universidade Federal do Rio Grande do Sul (PPGLet/UFRGS). Bolsista de Doutorado da Capes. Mestre em Letras pela PPGLet/UFRGS.
} 
(naturalizadas) do cotidiano. Heroínas de suas próprias vivências, a identidade de fala das autoras que compõem a antologia está atrelada aos distintos modos de ser e estar em uma determinada realidade. Os textos de Querem nos calar (2019) salientam que não basta estar no mundo: é preciso ser ouvida. E tendo em vista que a literatura é um direito humano, essas vozes em refrão na literatura brasileira perpetuam suas existências através da escrita, reiterando que as práticas de apagamento e quietude, com elas, não funcionam: as vozes possantes que ecoam por meio de seus textos sempre falarão mais alto, mostrando-se explícitas, originais, assumidamente em desajuste com a norma.

O livro é constituído por textos literários de autoria de quinze poetas, artistas, slammers, historiadoras, rappers, atrizes, MCs, arte-educadoras, diretoras, professoras, pesquisadoras e produtoras culturais provindas das cinco regiões do país. Desse modo, segundo a curadora Mel Duarte, tenta-se contemplar as muitas variações locais e artísticas da "poesia falada" atualmente. Embora não seja uma tarefa fácil - devido à vasta representatividade e o caráter múltiplo das produções abarcadas por esse movimento poético - a antologia consegue delinear precisamente as diferenças e as principais poéticas regionais que hoje são parte da cena do poetry slam no Brasil. Em linhas temáticas, e de Norte a Sul do país, as vozes das quinze autoras ora aproximam-se, ora distanciam-se, mas a finalidade que as reúne na antologia é a mesma: falar, e falar alto. Ainda que estruturalmente a linguagem falada seja o que, de fato, constitui estes textos - as marcas de oralidade são evidentes, seja nos textos narrativos, seja nos poemas - a dinâmica dessa fala assume um caráter político-poético em todas as produções presentes no livro. É uma fala de perceptível contestação, mas também uma fala que projeta possibilidades por meio dos afetos distendidos pela poesia.

Durante toda a coletânea, as vozes das autoras simulam um encontro, em um exercício em que uma faz eco a voz da outra. Uma noção de coletividade paira sobre a obra, interligando os dizeres poéticos em uma ampla e intrigante rede na qual as existências das mulheres visualizam, a partir do olhar e do lugar da outra, uma amistosa ressonância. No que compete à organização da antologia, cada uma das autoras assume uma seção no livro, dada por meio de ordem alfabética. Sendo assim, os textos apresentados em Querem nos calar (2019) seguem a seguinte disposição: primeiro, os poemas de Anna Suav, em seguida, Bell Puã, Bor Blue, Cristal Rocha, Dall Faria, 
Danielle Almeida, Laura Conceição, Letícia Brito, Luiza Romão, Luz Ribeiro, Mariana Felix, Meimei Bastos, Negafya, Roberta Estrela D’Alva, e por último, os textos de Ryane Leão.

A apresentação do livro, estrategicamente intitulada de "rompendo o silêncio através da poesia falada", é assinada por Mel Duarte. Ao focalizar o espaço ocupado pelas mulheres dentro do poetry slam, Duarte frisa que é nítido o quanto as poetas, de modo geral, contribuíram para a mudança do "conceito de poesia, tirando-a do pedestal hegemônico pelo qual sempre nos foi apresentada e provando que a escrita e a fala de uma mulher pode mudar padrões sociais" (DUARTE, 2019, p. 10). Ainda na apresentação do livro, a poeta e slammer destaca o papel e a função social e cultural da poesia falada na realidade brasileira, e resgata, para isso, algumas das linhas de origem do poetry slam no país. Duarte justifica a realização da obra como uma execução que se contrapõe ao peso do silenciamento histórico imposto às mulheres, e reafirma que a característica de "livre diálogo" do poetry slam viabiliza não apenas um espaço de compartilhamento, da fala autoencenada, mas que este espaço também configura um convite à escuta, colocando em perigo as versões decorrentes de uma história única.

O prefácio, composto por Conceição Evaristo, enfatiza o caráter coletivo e dialógico da obra, e a própria autora sublinha que na antologia "as falas de outras mulheres, assim como a minha, se compactuam" (EVARISTO, 2019, p. 13). Evaristo discorre que o ato de falar é equivalente ao ato de se apropriar de uma perspectiva. Há, nesse gesto autoral efetivado pelas poetas, um incumbir-se da autoria do próprio destino. Esse posicionamento autoral, que instiga e prioriza a errância, também impacta no modo como esses textos são gerados e apresentados pelas autoras. Destituídos de formalismos estéticos e normas consideradas certas e puristas, o jogo de linguagem dessas composições é calcado na chamada "gramática do cotidiano". Nessa ação, há também uma reflexão sobre a língua dominante, bem como sobre as imposições e prescrições impostas por ela. Em um texto cujo cerne é a performance através da voz e da presença, as autoras intentam aparecer dotadas de uma lírica própria, uma vez que, segundo um dos poemas de Cristal Rocha, é característico da mulher que escreve nascer dependente de lírica.

A presentidade do corpo no momento da performance poética convoca o leitor para um momento de fruição desse evento amplificado pelo poema. Tem-se a 
manifestação, por meio da leitura, de facetas da subjetividade que são dadas por meio da intensidade vocal e corporal dos textos. A autoencenação de um "eu" aliada à carga dramática e performática característica do poetry slam oportuniza que novas construções sejam estabelecidas pela dimensão dialógica da voz.

Nos poemas de Anna Suav, essa dimensão dialógica da fala centraliza os movimentos que o corpo da mulher negra e periférica faz em espaços distintos, posto que é a movimentação, contrária ao comedimento, que abre brechas naquilo que a voz poética denomina de "sistema bruto": "Não tenho pressa, mas se eu corro, ninguém vai me segurar". (SUAV, 2019, p. 22). E se a imagem da corrida, ainda que metafórica, aparece como um meio de fuga nos textos da coletânea, Bell Puã convoca todas as mulheres, "histéricas, vadias, putas, bruxas/queimadas na fogueira da inquisição/assediadas por parentes, pelo patrão/por amigos, desconhecidos e até líder de religião" (PUÃ, 2019, p. 30) para se retirarem dos sistemas tirânicos, e levantarem voo.

Nos escritos de Bor Blue, as tentativas de resgatar e vivenciar as heranças culturais são um dos canais de força da performance textual. Um apreço pelas "raízes" é destacado, e a força da voz poética provém do descontentamento: "Me tiraram do mato e me transformaram nisso, contra minha vontade". (BLUE, 2019, p. 46). A lembrança e a negação a uma determinada cultura e a hábitos que não são próprios da sua subjetividade se encontram com o retrato de solidão da mulher negra estampado no poema "Ressurreição", de Dall Farra. Mesmo distintas, as duas solidões relatadas se encontram na imagem uma da outra, apoiando-se, pois "Mesmo que me matem/Acharei a trilha dos imortais", declara a voz no poema. E a morte é a razão pela qual o protesto é esboçado em "Genocídio", poema de Danielle Almeida: "Aumenta o número de mortos indígena.../Eles morrem pedindo demarcação.” (ALMEIDA, 2019, p. 81). A figura de um país genocida também é pintada no poema "Brasil Genocida", da poeta Negafya. Solidárias e impacientes com as situações que integram os seus cotidianos, as vozes de Querem nos calar (2019) também objetivam o estabelecimento de uma equidade. São vozes que buscam refletir sobre as razões de depreciação do universo feminino. Nesse exercício, o "Poemas dos Porquês", de Laura Conceição, auxilia na compreensão das disparidades: "Por que o rap feminino não tem visibilidade?/E esporte feminino não tem visibilidade?/Nem a arte feminina tem visibilidade?/E mulheres são descartadas quando/É visível a idade?” (CONCEIÇÃO, 2019, p. 87). 
Um pensamento acerca das indiferenças também percorre os escritos de Letícia Britto. Recortes de um cotidiano específico expõem a fragilidade de determinados grupos mediante as prescrições autoritárias e legitimadas no âmbito social: "Homens da lei que matam crianças/Homens que fazem leis que condenam mulheres/Corpos pretos que sofrem a paixão e a ira, mas quase nunca o afeto" (BRITTO, 2019, p. 102). Os elementos e os diálogos intertextuais (seja com a música, com a literatura, e/ou com a arte), aparecem como característica evidente nas produções de Querem nos calar (2019), especialmente nos poemas de Luiza Romão. E é retomando esse espaço da intertextualidade e da memória que o poema "Espancaestanca", de Luz Ribeiro, delineia a cena do trauma: "quem estanca o que a memória espanca?" (RIBEIRO, 2019, p. 129).

Em "Manas", um dos poemas de Mariana Félix, a palavra se apresenta como uma ferramenta que reverte às situações de submissão do corpo-mulher. Nos escritos de Meimei Bastos, destaca-se que ainda há muito que se fazer, e que apesar de vivermos "tempos ensolarados/daqueles de deserto,/sem nenhuma miragem,/temos areia nos olhos/e quase nenhuma esperança" (BASTOS, 2019, p. 174), esse é o momento em que os enfrentamentos devem ser feitos com ainda mais afinco. Para Roberta Estrela D’Alva, uma das formas de enfrentamento está na ampliação das práticas artísticas exercidas pelas mulheres: "Nossa criação/é a solução/A arte como espada para vencer a opressão". (D’ALVA, 2019, p. 194).

E "a poeta que não sabia que era poeta/e com sua voz hoje invade/os quatro cantos” (LEÃO, 2019, p. 208) como relata um dos poemas de Ryane Leão, é a jovem escritora que, inserida no movimento de poetry slam, faz da performance poética um momento em que a abertura dos códigos de linguagem estabelece pontes entre a cultura e a vida. Em decorrência dessas relações, novos sentidos e contornos epistemológicos são ocasionados. A coletânea Querem nos calar (2019) faz do evento da poesia um momento de densidade, orgânico. E se toda voz inaugura um corpo, as vozes em refrão - e em ebulição - da poesia do presente, por meio de novas e infindáveis experimentações, estão a inaugurar novos horizontes, povoados por corpos que jamais, sob nenhuma hipótese, vão parar de falar. 


\section{REFERÊNCIAS}

BARTHES, Roland. O grau zero da escrita: seguido de novos ensaios críticos. Trad. Mario Laranjeira. São Paulo: Martins Fontes, 2004. (Coleção Roland Barthes).

COHEN, R. Performance como linguagem. São Paulo: Perspectiva, 2007.

GUATTARI, Félix. Caosmose: um novo paradigma estético. Trad. Ana Lúcia de Oliveira e Lúcia Cláudia Leão. São Paulo: Ed. 34, 2008.

PUCHEU, Alberto. "Performance para um corpo concentrado em sua voz". A fronteira desguarnecida (poesia reunida 1993-2007). Rio de Janeiro: Azougue Editorial, 2007.

ZUMTHOR, Paul. Escritura e Nomadismo: entrevistas e ensaios. Trad. Jerusa Pires Ferreira, Sônia Queiroz. Cotia, SP: Ateliê Editorial, 2005.

Performance, recepção, leitura. Trad. Jerusa Pires Ferreira, Suely

Fenerich. São Paulo: Cosac Naify, 2007. 